ESSAY

\title{
Development of ecologically meaningful, multiple-species conservation strategies under the California and U.S. Endangered Species Acts
}

\author{
ERICA FLEISHMAN ${ }^{1, *}$, T. LUKE GEORGE 2 , ERIC C. HANSEN ${ }^{3}$, \\ AND JULIE HEINRICHS ${ }^{4}$
}

${ }^{1}$ College of Earth, Ocean, and Atmospheric Sciences, Oregon State University, Corvallis, OR 97331, USA

${ }^{2}$ Department of Fish, Wildlife and Conservation Biology, Colorado State University, Fort Collins, CO 80523, USA

${ }^{3} 4200$ North Freeway Boulevard, Suite 4, Sacramento, CA 95834, USA

${ }^{4}$ Natural Resource Ecology Laboratory, Colorado State University, Fort Collins, CO 80523, USA

*Corresponding Author: erica.fleishman@oregonstate.edu

The California and U.S. Endangered Species Acts prohibit take of protected species, but allow for authorization of take incidental to otherwise lawful activities provided the take is minimized and mitigated. Incomplete and inconsistent ecological information can limit the contribution of mitigation plans for incidental take, especially those for multiple species, to species persistence. Many such plans focus on acquisition and management of coarse-resolution land-cover or land-use types. These classifications may not coincide with a species' resource requirements (its habitat) or the greatest constraints to its viability. Complementing acquisition with rigorous research on population biology, stressors, and habitat use and quality may be much more effective than preservation of putative but unproven habitat. Such adaptive conservation can be applied to species with restricted or extensive distributions. When the distribution and ecology of geographically restricted species are well-known, then connectivity analyses, sometimes complemented by spatially explicit, mechanistic population models, may inform habitat acquisition and management. When little information exists on the ecology or vital rates of a restricted species, we suggest assessment of occupancy, habitat use, or demography; tracking individuals' movements; and evaluation of habitat quality. Acquisition and management of local lands that may not serve as habitat is unlikely to contribute to conservation of extensively distributed species with range-wide declines. Instead, we suggest that conservation efforts for these species emphasize strategic acquisition of open space 
(large, undeveloped areas that are more likely to serve as high-quality habitat), potentially in locations distant from the permit area. The above areas of research can inform optimization of conservation locations. Many mitigation decisions are based on assumptions drawn from limited data. Inclusion of scientific research in development and implementation of mitigation plans for incidental take can strengthen the plans' information content, improve the ecological success acquisition and management, and advance conservation of protected species.

Key words: adaptive management, connectivity, demography, habitat quality, mitigation, occupancy, optimization, population models, reserve management, spatial prioritization

Conservation of species listed under the California Endangered Species Act (CESA; California Fish and Game Code sections 2050-2089.25) or U.S. Endangered Species Act (ESA; U.S. Code, Title 16, sections 1531-1544), especially on private lands, is hampered by ecological information that is limited and often is inconsistent among species and locations, and by the difficulty of reliably estimating species-specific effects of allowable land uses. These gaps in understanding make it difficult to evaluate whether conservation actions, including acquisition of potential habitat, are likely to compensate for the effects of ongoing land use and other regulated activities. Gradual, optimized establishment of conservation areas that is augmented by species-specific research may enable adaptive management that allows protected species to persist locally and regionally. Here, we focus primarily on terrestrial species on private lands, but much of our discussion is transferable to aquatic species and public lands.

\section{Permits for Incidental Take}

The CESA and ESAs prohibit the take of species, subspecies, or, under the ESA, distinct population segments (collectively referenced herein as species) listed as endangered or threatened. The CESA also prohibits take of species that are candidates for listing. In general, exceptions are made, via permit, if the take is incidental to otherwise lawful activity and will not jeopardize the continued existence of the species. Under the ESA, individuals or entities that are proposing actions that do not require other federal permits, approvals, funds, or actions, and therefore are ineligible for Section 7 consultation, may apply for incidental take permits under Section 10(a). The applicant's habitat conservation plan (HCP) details how they will meet requirements for issuance of an incidental take permit. The ESA requires that an HCP specify the effects of the take and the steps that will be taken to minimize and mitigate those effects.

The CESA conditions issuance of incidental take permits on minimization and full mitigation of the impacts of the proposed taking. It is unlawful to take a species listed under the CESA, regardless of whether it is listed under the ESA, without additional state authorization. Individuals or entities may obtain an incidental take permit under Section 2081(b) of the California Fish and Game Code provided that the impacts of the proposed take are minimized and fully mitigated. If a species is listed under both the ESA and CESA, and an incidental take statement or permit is obtained under Section 7 or 10(a), respectively, of the ESA, then the California Department of Fish and Wildlife may determine that the federal authorization is sufficient to fulfill the requirements of the CESA. California and federal 
law allow for some other exceptions to the take prohibitions. For example, Safe Harbor Agreements encourage voluntary conservation by landowners that will contributes to species recovery, and some scientific, educational, and management activities are eligible for permits.

Minimization and mitigation plans for incidental take under the CESA, or HCPs for such take under the ESA, may be developed for a single species or for multiple species (for simplicity, although the language of the CESA and ESA differ, we henceforth use mitigation plans to encompass the requirements of both acts). In California, plans may be developed for species that are listed or candidates for listing under the CESA. Federal plans may be developed for species that are listed or that may be listed over the duration of the permit. In recent years, the agencies that implement the ESA (US Fish and Wildlife Service and National Marine Fisheries Service) generally have discouraged inclusion in incidental take permits of species for which the likelihood of listing is low, data to inform conservation actions are quite limited, and occurrence in the plan area is uncertain (e.g., USFWS and NMFS 2016). Nevertheless, because private landowners generally seek assurances that future listings of species will not incur additional financial burdens or land-use restrictions, it is not uncommon for federal incidental-take mitigation plans to cover unlisted species. For example, of the 168 HCPs approved in Region 8 (California and Nevada) as of March 2020, 50 included taxa that were not listed under the ESA (ECOS 2020). In many cases, these species are designated as taxa of conservation concern by resource management agencies or taxonomic authorities.

\section{Concepts of Habitat in Mitigation Plans for Incidental Take}

At both the California and federal levels, most species-specific mitigation plans focus on reducing threats to the species, acquiring areas that appear to function as habitat for the species, or increasing the quality and configuration of the species' habitat. Habitat, a species-specific construct, encompasses the space within which a species lives or can live and the abiotic and biotic elements in that space that generally are required for survival and persistence (Hall et al. 1997; Morrison and Hall 2002). The quality and configuration of a species' habitat affect its population dynamics and relations with other species (Pulliam 1988; Dunning et al. 1992; Watkinson and Sutherland 1995) and its connectivity, usually defined as the probability that genes or individuals move among patches of the species' habitat (McRae 2006; McRae et al. 2012). Although habitat is a central concept in plans to mitigate incidental take, plans use many different methods to assess habitat.

The ecology, and the breadth and depth of ecological knowledge, of species that are included in a plan for mitigation of incidental take varies. Gaps in demographic, environmental, and genetic data are common, even for listed species. The gaps can be exacerbated when a species occurs largely on private land to which access is relatively limited. In such circumstances, detailed understanding of phenomena affecting survival and reproduction across the species' range or within a given region often is limited. Even the information on occurrences that is included in many mitigation plans, particularly for species that are not listed, may not be collected or collated rigorously. The California and federal endangered species permitting agencies generally require an assessment of whether a given species has been documented or reasonably might be expected to occur in the planning area. Applicants often base these determinations on a limited number of surveys, complemented by searches of Natural Heritage Program or similar data, and the use of vegetation or other biotic or abiotic attributes as surrogates for habitat. The latter sources have limited information content 
because they rarely account for observed absences, detection probability (the likelihood of observing a species given its presence; MacKenzie et al. 2003), temporal variation in presence and abundance, or the fact that presence may be transient and not reflect local recruitment.

The manner in which a species' habitat is represented in plans for mitigation of incidental take under the CESA and ESA may not fully reflect existing knowledge about habitat structure, composition, and function. Instead, descriptions and quantifications of habitat tend to rely on coarse-resolution land-cover or land-use types (e.g., grassland, pasture, shrubland, woodland, wetland). For example, the Pacific Gas \& Electric Company San Joaquin Valley Operations and Maintenance HCP and Section 2081(b) permit estimated the percentage of area of 14 land-cover and land-use types within the plan boundary that might function as habitat for 48 species that were covered by the permits (Jones and Stokes 2007). Similarly, the South Sacramento HCP (which also received a Section 2081(b) permit for seven species listed under CESA) included a binary classification of whether 17 land-use and land-cover types were associated with potential presence of 29 covered species (County of Sacramento et al. 2018). Coarse representations of habitat make it difficult to estimate occupancy, abundance, survival, and reproduction, and therefore to identify the factors that most constrain survival and reproduction, the actions most likely to increase the species' survival and reproduction, and metrics of success. Several multiple-species HCPs in California incorporated the concept of umbrella species, or species that, if conserved, will confer protection to numerous co-occurring species (Gerrard et al. 2001; Winchell and Doherty 2008). Again, however, unless the distribution and habitat of hypothesized umbrella species and co-occurring species is evaluated rigorously, conservation of the umbrella or its habitat is unlikely to achieve comprehensive conservation objectives (Hitt and Frissell 2004).

\section{Adaptive Management in Mitigation Plans}

Many mitigation plans include adaptive management of varying degrees of scientific rigor. For example, the East Bay Municipal Utility District Low Effect HCP (https://ecos. fws.gov/ecp0/conservationPlan/plan?plan_id=3505) includes triggers for changes in management activities that relate to reproduction of several species. In most cases, the outcomes of management are assessed, but alternative management methods are not treated as formal experiments.

Ideally, the scientific information provided by adaptive management will benefit not only the plan area and species that use that area but other conservation efforts in the region, reducing the need for redundant research and, in turn, increasing the cumulative funds available for conservation of habitat (Wilhere 2002). However, existing adaptive management programs for private lands under the CESA and ESA generally were developed for reserves that were designed relatively early in the planning process as a primary mitigation measure, even when data were limited. Because reserves sometimes are designated if they meet coarse land-cover criteria, evidence that the area is viable habitat or occupied by the species may be sparse. We believe there are ecological benefits to conservation of open space. Nevertheless, without strong indications that reserves indeed are high-quality habitat and contribute to a species' viability, investments that are alternatives to rapid designation of reserves may have greater long-term value. We suggest that research on population biology, stressors, and habitat use and quality provides the best scientific data to inform reserve acquisition and management and to increase the likelihood that mitigation will meet conservation goals. Complementing mitigation planning and implementation with research, which we 
reference as adaptive conservation, ultimately may contribute far more to the long-term viability of a species than preservation of marginal habitat that may not support reproduction and recruitment of the covered species. Although the state and federal endangered-species regulatory agencies rarely equate research with mitigation, others (e.g., Wilhere 2002) have proposed that mitigation credits be allocated for provision of information that is applicable to regional conservation.

Here, we outline how adaptive conservation in the context of a multiple-species plan to minimize and mitigate incidental take can ameliorate data gaps and increase the effectiveness of conservation efforts. Such needs are exacerbated for species that have extensive distributions and are declining across much of their range. We consider development of an adaptive conservation strategy for taxa for which local ecological knowledge and conservation options are highly variable. We introduce flexible methods for integrating multiple sources of data to optimize identification of potential locations for mitigation. These methods link research to action, including adaptive management. We consider adaptive conservation options for three types of species: an ecologically well-known species with a geographically restricted distribution, a geographically restricted species for which data are limited, and a species with a geographically extensive distribution. Although these classes of species do not encompass the full possible range of distributions and data that might be addressed in conservation plans, we believe that they are among the most common and challenging.

\section{ECOLOGY WELL KNOWN, DISTRIBUTION RESTRICTED}

If a species' distribution is relatively constrained (e.g., a regional endemic), its ecology is fairly well known, and the quantity and quality of its habitat have been assessed rigorously and appear to be sufficient, then connectivity analyses may have considerable potential to inform adaptive conservation, including habitat acquisition and management. Efforts to conserve species are more likely to be effective when populations or areas that function as habitat are connected rather than isolated (Harris 1984; Hanski 1999). Connectivity is affected by topography; the built environment; vegetation composition, structure, and configuration; and ecological processes, such as fire or flows of water and nutrients. Assessment of connectivity provides information that may be relevant to identifying areas through which individuals can move among discrete populations or patches of habitat, thus facilitating gene flow and recolonization (Loss et al. 2011). High connectivity also can increase the resilience of populations to changes in land cover, land use, and climate, and minimize or facilitate the spread of non-native invasive species (Glen et al. 2013) or other undesirable environmental changes (Gray and Dickson 2015). Genetic data can be used as data inputs or to evaluate the outputs of analyses that did not include genetic data.

Different methods of assessing connectivity are useful in different situations. For example, methods based on graph theory (e.g., Urban and Keitt 2001; Bodin et al. 2006) represent an area as a set of nodes (patches of habitat or other discrete areas) connected to some extent by edges. Edges are functional links between pairs of nodes (e.g., populations in discrete patches linked by dispersal) that efficiently can represent simple connections among populations. Methods based on circuit theory (McRae 2006; McRae et al. 2008) are relatively flexible and incorporate maps of environmental heterogeneity that are known or assumed to affect animal movement. Circuit theory explicitly evaluates how topography, land cover, and other abiotic and biotic attributes affect the potential movements of individuals. Circuit-theory based methods are used to predict genetic and ecological effects 
of environmental change, and to identify high-priority areas for maintaining or increasing connectivity. Such methods can be applied to diverse data, including coarse-resolution distribution maps, simple maps of habitat and nonhabitat, complex spatial data, or data on multiple species (Fleishman et al. 2017). Models that are based on circuit theory simultaneously consider all possible pathways that might connect pairs of populations. By extension, the models indicate probability of gene flow and landscape conditions that may impede genetic differentiation. Empirical validation of such estimates with genetic data is rare, but informative. For example, analyses of the genetics of giant gartersnakes (Thamnophis gigas), a species listed as threatened under the CESA and ESA, revealed relatively recent levels of genetic exchange (breeding) among populations (via genetic similarity) (Wood et al. 2015).

Spatially explicit, mechanistic population models (Schumaker et al. 2004; Schumaker and Brookes 2018) include mechanisms to simulate connectivity within the context of a population viability model so that connectivity is one of multiple factors that may affect probability of persistence. Spatial individual-based models such as HexSim (Schumaker and Brookes 2018) create connectivity outputs that are similar to those produced by circuitbased analyses but include greater biological realism by considering dispersal behavior and population demography and dynamics. The mechanistic simulations created by such models link the behavior and fates of individuals to their locations, supporting evaluation of the effects of environmental change on movement, population sizes, distributions, and genetic diversity (e.g., Heinrichs et al. 2019a, 2019b; Nogeire-McRae et al. 2019). Accordingly, the results of these models can project the population-level effects of barriers to movement and alternative reserve designs and be applied to examine the effects of compensatory mitigation (Barbosa et al. 2019). If there is a desire to project future occupancy given potential changes in land use or land cover, such changes can be simulated by modifying the input environmental data layers. If interactions among species, whether mutualistic or antagonistic, are known or hypothesized to affect species' distributions, then it is possible to model the interactions and resulting distributions of multiple species simultaneously. For example, HexSim models of the Northern Spotted Owl (Strix occidentalis caurina), a subspecies listed as threatened under the CESA and ESA, were developed to inform recovery plans and to model competitive interactions with Barred Owls (Strix varia) (USFWS 2011; Schumaker et al. 2014; Dunk et al 2019). These types of analyses can support defensible conservation decisions and contribute to selection of mitigation actions and locations that will increase the likelihood of species persistence.

As described below, reserve selection or other prioritization algorithms then can be used to integrate the results of distribution and connectivity analyses, and other considerations, to prioritize lands for multiple uses, including research, preservation, and economic activities compatible with conservation. These algorithms can be applied across extensive areas to optimize the quantity and connectivity of habitat for one or more species given different scenarios of environmental change (Margules and Pressey 2000; Moilanen and Kujala 2008). The outputs of any connectivity analyses can become additional data layers in iterative optimization analyses. For example, both occupancy and connectivity could be included in optimization runs. In the case of the Northern Spotted Owl, the outputs of spatially explicit, individual-based population models were used in a prioritization algorithm (Zonation; Moilanen et. al 2009, 2014). The algorithm estimated and compared the dynamics of simulated populations of Northern Spotted Owls among a suite of candidate habitat networks, which varied in size and configuration, given alternative scenarios of future habitat quality and interactions with Barred Owls (Dunk et al 2019). 


\section{ECOLOGY UNCERTAIN, DISTRIBUTION RESTRICTED}

In some cases, a species' range may be known to be limited, but little information exists on the species' occupancy, habitat use, or vital rates (birth, death, immigration, and emigration). In these cases, we suggest four high-priority areas of research that can inform adaptive conservation: assessment of occupancy or habitat use, tracking the movements of individuals (often via radio or global positioning system [GPS] telemetry), demographic characterization, and assessment of habitat quality.

\section{Occupancy or Habitat Use}

Estimation of occupancy or habitat use requires robust sampling that allows estimation of detection probabilities (MacKenzie et al. 2006). If a population is fairly open, occupancy models may estimate transient exploitation of resources or habitat use in a given location rather than consistent presence. Existing data often are insufficient to model presence, let alone occupancy, of a given rare species. Many observations of rare taxa have not been reported to publicly accessible data sources, such as the California Natural Diversity Database, so presence of the species in any given area may be underrepresented in public data. Furthermore, some records may reflect misidentification and may be biased towards locations near roads (Kadmon et al. 2004). Because inferences generally become stronger as sample sizes and the spatial extent of sampling increase, it is ideal to collect occupancy data with a spatially balanced design from as many locations over as much of the species' range as possible. Environmental DNA (eDNA) may be an effective means of establishing simple presence of terrestrial or aquatic species that are difficult to sample or cryptic (Bálint et al. 2018; Schumer et al. 2019). For example, the method has been applied to detect bull trout (Salvelinus confluentus), a species listed as endangered under the ESA (McKelvey et al. 2016), and endangered Gouldian finches (Erythrura gouldiae) in Australia (Day et al. 2019). However, environmental DNA usually does not allow one to obtain the precise coordinates or time at which a species was present, and it can be less effective in lotic than in lentic systems (Rees et al. 2014).

\section{Tracking Movement}

Tracking multiple individuals of a species - in multiple populations, if applicablethroughout their annual or reproductive cycle provides information on occurrence (and, by extension, habitat use), the locations and attributes of home ranges, movement distances during multiple life stages, and behavior, potentially including interactions among individuals. Presence alone, especially of long-lived species, may not indicate recruitment and long-term viability. Therefore, assessment of population-level demography over multiple (often three or more) years or reproductive cycles allows for association of birth, death, emigration, and immigration rates with variation in climate, land use, and other abiotic and biotic environmental attributes.

Telemetry data can help inform assessment of connectivity. For example, it can identify barriers to movement or sources of mortality of vertebrates such as desert bighorn sheep (Odocoileus hemionus) and pronghorn (Antilocapra americana), various subspecies and populations of which are listed under the CESA and ESA and by the Navajo Nation (Fleishman et al. 2017). Moreover, telemetry data can reveal the locations and attributes of 
habitat features that rarely are used, but are essential to survival and reproduction, such as nesting locations or neonatal movements of herptiles (Forsythe et al. 2004).

Advances in miniaturization are making telemetry more feasible, especially for relatively small animals. It widely is accepted that a tracking device should not exceed 3-5\% of an animal's weight. Until recently, most GPS transmitters were too heavy to affix to small-bodied taxa, such as bats. However, GPS tags with weights of 1.45-180 g now are available, and field tests indicated that their accuracy is acceptable for some applications (e.g., bats, Conenna et al. 2019; giraffes, Hart et al. 2020). Another new technology, the Motus Wildlife Tracking System, receives individually identifiable signals from UHF tags within a line-of-sight distance of about $15 \mathrm{~km}$ (Taylor et al. 2017). There are, of course, limitations to these methods. For example, the smallest GPS tags require recapture of the animal or retrieval of the tag, and the Motus system relies on fixed receiving stations. Nevertheless, ongoing innovations almost certainly will continue to increase the practicality of tracking.

\section{Demography}

Research on survival, reproductive success and recruitment often increases understanding of management actions that are consistent with population growth and stability. Effective conservation of any species relies on increasing values of demographic parameters that may be limiting viability. Integrated population models use information on population size, survival, and reproduction to project rates of population change and identify factors that affect those rates of change (Kéry and Schaub 2012). Mark-recapture is among the methods that provide data for demographic analyses, but is not feasible for many species, such as those that migrate across large distances or cannot survive being handled multiple times. Resighting, recapture, or recovery of marked individuals allows estimation of apparent survival (survival minus permanent emigration) if marked individuals are followed for three or more time intervals. Furthermore, mark-recapture analyses can provide estimates of stage-specific survival that, when coupled with estimates of stage-specific fecundity, can identify the age class or classes that make the greatest contribution to population growth (Crouse et al. 1987).

\section{Habitat Quality}

It is helpful to evaluate habitat quality rigorously rather than simply assessing environmental associations with occupancy or abundance. As an example, evaluation of relations among the demography or physical condition of a target species, composition and abundance of prey, climate and other abiotic variables, and land uses (e.g., agriculture, recreation) can inform estimates of the degree to which these factors affect habitat quality and are useful for habitat evaluation in the context of reserve design and management. For instance, food availability and pre-migratory fat deposition in Northern Waterthrushes (Seiurus noveboracensis) varied along a moisture gradient, allowing for inference to habitat quality (Smith et al. 2010). Similarly, comparison of long-term occupancy and fledgling production provided indications of habitat quality in Eagle Owls (Bubo bubo) (Brambilla and Bionda 2013). Yet some elements of habitat quality, such as prey base, rarely are evaluated and documented. Instead, inferences about the quality of foraging habitat largely are anecdotal. However, conventional wisdom about land-cover types or other ecological attributes that represent the highest-quality foraging habitat is not always consistent with data on availability of prey or spatial and temporal variation in space use (Fleishman et al. 2016). 


\section{EXTENSIVE DISTRIBUTIONS}

Some unlisted species that are included in plans to mitigate incidental take under the CESA or ESA have geographically extensive distributions and are declining across much of their range, often as a result of widespread habitat loss and reductions in habitat quality (generally acknowledged as the greatest threats to species; Wilcove et al. 1998). Many such species, especially birds, are designated as species of special concern by federal or state resource agencies. For example, the Coachella Valley Multi-Species HCP, which also received a permit from California under sections 2800-2835 of the state's Fish and Game code, included Yellow Warbler (Setophaga petechia), which breeds across Canada and the northern two-thirds of the United States. In these cases, acquisition and management of local reserves is unlikely to have appreciable relevance to the species' regional or global status; opportunities to acquire areas that are known to be seasonally meaningful, such as major breeding or stopover grounds, are unusual. Migratory species may be affected by threats in either their breeding or wintering range, and when species traverse political boundaries, jurisdiction over such threats becomes more fragmented. Furthermore, the status and trends of such species often are asynchronous among regions. When potential habitat for these species, especially foraging habitat, is widespread, a considerable proportion of an ecosystem conceivably could qualify as habitat. Presence or even reproduction of the species in reserves will not necessarily indicate high-quality habitat quality, and absence or departure of the species from conservation areas will not necessarily indicate low-quality habitat.

Instead, we suggest that adaptive conservation for these species emphasize strategic acquisition of open space (large, undeveloped areas that may serve as high-quality or wellconnected habitat for the listed species and other native species), potentially in locations relatively distant from the permit area, rather than attempts to conserve local areas that likely have low habitat quality or effectively do not function as habitat. Conservation of locations near the permit area where individuals sporadically are detected may not contribute meaningfully to conservation of the species, and conserving all possible locations in which the species might occur vastly overestimates habitat amount and is not feasible. By extension, ad hoc conservation of locations in which the species conceivably will occur is unlikely to contribute to regional viability. We acknowledge the challenges to acquisition by local governments that do not have jurisdiction outside the permit area, or to mitigation outside California for species that are listed under the CESA but not the ESA. Three research foci may contribute to identification of regions in which to concentrate conservation efforts: models of the full life cycle of the species, spatially extensive analyses of occupancy or abundance, and analysis of genetic structure over as large an area as possible. The first can help to identify life stages that contribute the most to survival, reproduction, and recruitment, potentially focusing conservation efforts on locations that may be distant from the area in which take is permitted. The second may identify locations, or environmental attributes, that are most closely linked with consistent occupancy or relatively high abundance. The third can delineate genetically distinct populations and, as discussed above, connectivity among populations.

\section{SPATIAL PRIORITIZATION}

Optimization models, which often are applied to reserve design, can inform development and implementation of plans for mitigation of incidental take (e.g., USFWS and 
NMFS 2016). The areas of inquiry described above can help to increase the reliability of data layers for each species included in the optimization. Of the available methods, Zonation (Moilanen 2007; Moilanen et al. 2009, 2014) is among the most applicable to mitigation plans for incidental take. Zonation is a free, publicly available method for spatial planning that hierarchically prioritizes locations for conservation - or any other land use - on the basis of desired attributes or objectives. Desired attributes may include but are not limited to stable populations of protected species or particular environmental features or land uses. These attributes may be given equal or unequal weights. Population genetics, connectivity, economic costs of acquisition or management, and stressors to species or their habitat (e.g., proximity to urban development) readily can be incorporated into the analyses. The outputs are compatible with decision-making in the context of multiple, and potentially competing, land uses. Because the optimization is straightforward to iterate, it can accommodate new data, advances in ecological understanding, and changes in social or environmental conditions, thereby informing phased acquisition of conservation areas (Di Minin et al. 2014).

Zonation optimization models are applied to grid-based data, often known or hypothesized species' distributions (including probability distributions, such as detection-weighted occupancy or abundance), or habitat locations, topography, potential for acquisition or easements, and other environmental data layers. Therefore, the process is compatible with geographic information systems (GIS) and statistical models of species' distributions. Furthermore, cloud computing, such as Google Earth Engine, has made integration of remotely sensed data in such processes much more feasible and rapid. Optimizations in Zonation rank all locations (e.g., pixels or cells within the grid) on the basis of their potential contribution to conservation or other objectives. The ranking is achieved by an iterative process of cell removal, which starts with the full study area (or part of the study area, such as areas within a given set of jurisdictional boundaries) and removes cells in the order that minimizes the marginal loss of targets at each step. The value of remaining cells to all species or other targets is re-evaluated after each removal step because the relative priority of a given cell may change after other areas are removed. The result of this process is a hierarchical ranking that can be used to identify the highest-priority locations (e.g., the most efficient conservation network) for any total area conserved.

Optimization allows one to account for aggregation, or the principle that all else being equal, fewer large conservation areas are preferable to many small conservation areas. Multiple ways of accounting for connectivity are possible. The process also allows one to analyze replacement costs (the difference between the value of the optimal solution for meeting the objectives and the value of a different solution) to compare the ecological priority or economic cost of alternative reserve configurations.

There are many examples of practical applications of optimization modeling via Zonation. For example, the Finnish government uses such optimization to support implementation of METSO, a program to conserve biological diversity in its privately owned southern forests (Mikkonen et al. 2018). For more than a decade, the Victoria (Australia) Department of Environment, Land, Water and Planning has used similar methods to inform its regulatory and investment decisions across extensive areas because it allows for objective, transparent, and repeatable ranking of the relative contribution of different areas (or actions) to management objectives. Moreover, by producing hierarchical rankings that are not dependent on explicit area or cost targets, outputs are applicable to situations in which funding or the area that will be acquired for conservation is unclear. 
One might conduct an optimization analysis to identify areas with the greatest potential to contribute to the conservation goals of a given mitigation plan, which can be encoded in the analysis inputs and settings. Input data layers might represent existing and potential future development, existing preserves and conservation areas, probabilities of occupancy, connectivity, and habitat quality. Numerous settings can be adjusted to a particular context. For example, the Core Area Zonation cell removal rule uses the maximum (weighted) proportional representation of remaining habitat (the fraction of the total remaining habitat contained within each cell) across all species to rank cells for removal at each iteration. This removal rule seeks to maintain balanced (according to supplied weightings) habitat representation for all species at all stages of the removal process. Proportional representation is calculated with respect to the areas included in the analysis only.

Use of a generic edge-removal algorithm to prioritize structural connectivity (larger, more-connected areas of high predicted occupancy or associations with occurrence) tends to produce more-aggregated conservation networks. The edge-removal algorithm allows cells to be removed only from the edges of retained areas at each iteration ${ }^{3}$.

An iterative cell-removal process can remove existing preserves and conservation areas last. This will ensure that any new reserves complement existing conservation areas by targeting species that may not be conserved effectively within the existing areas. Removing existing preserves last also places higher priority on areas closer to those existing preserves, promoting structural connectivity of the expanded conservation network (Moilanen et al. 2014).

\section{CONCLUSIONS}

Many mitigation decisions must be made on the basis of assumptions and inferences drawn from limited data. Explicit implementation of new and scientific research that is targeted to the mitigation context can reduce reliance on unverified and potentially erroneous information. The latter may be particularly useful when the habitat quality or other ecological benefit of a potential mitigation acquisition is uncertain. The financial feasibility of gathering and analyzing new data inevitably is a concern. We suggest that research to fill knowledge gaps likely will yield a positive return on investments in both research and land acquisition, especially in regions where the cost of mitigation lands is likely to be high.

Mitigation plans for incidental take in California and at the federal level tend to rely on reserves and actions that are as close to the permit area as possible. However, especially when species have extensive distributions and are declining across their range, research may suggest that conservation actions in other regions are likely to make a greater contribution to long-term persistence of the species. The types of research we outline above also can strengthen adaptive management plans that otherwise might primarily emphasize vegetation maintenance or manipulation (e.g., ICF 2015; CVCC 2016). For example, rather than making assumptions about the attributes and quality of foraging habitat for widely distributed species, we suggest that targeted research on the composition and abundance of prey be used to inform acquisition and subsequent adaptive management.

Although research on the ecology of covered species is not heavily emphasized in design or implementation of most mitigation plans for incidental take, we believe that such research has considerable potential to guide effective investments in acquisition and adaptive management that minimize incidental take and contribute to recovery. 


\section{LITERATURE CITED}

Bálint, M., M. Pfenninger, H. Grossart, P. Taberlet, M. Vellend, M. A. Liebold, G. Englund, and D. Bowler. 2018. Environmental DNA time series in ecology. Trends in Ecology \& Evolution 33:945-957.

Barbosa, P., N. H. Schumaker, K. R. Brandon, A. Bager, and C. Grilo. 2019. Simulating the consequences of roads for wildlife population dynamics. Landscape and Urban Planning 193:103672.

Bodin, O., M. Tengö, A. Norman, J. Lundberg, and T. Elmqvist. 2006. The value of small size: loss of forest patches and ecological thresholds in southern Madagascar. Ecological Applications 16:440-451.

Brambilla, M., and R. Bionda. 2013. Variation in productivity and territory occupancy in an Eagle Owl Bubo bubo population. Ornis Fennica 90:50-56.

Conenna, I., A. López-Baucells, R. Rocha, S. Ripperger, and M. Cabeza. 2019. Movement seasonality in a desert-dwelling bat revealed by miniature GPS loggers. Movement Ecology 7:27.

County of Sacramento, City of Rancho Cordova, City of Galt, Sacramento County Water Agency, and Southeast Connector Joint Powers Authority. 2018. South Sacramento habitat conservation plan. Available from: ecos.fws.gov/ecp0/conservationPlan/plan?plan_id=554 (Accessed 29 October 2020)

Crouse, D. T., L. B. Crowder, and H. Caswell. 1987. A stage-based population model for loggerhead sea turtles and implications for conservation. Ecology 68:1412-1423.

Coachella Valley Conservation Commission (CVCC). 2016. Coachella Valley Multiple Species Habitat Conservation Plan, amended. Available from: https:/www.cvmshcp.org/Plan_Documents_old.htm\#plan (Accessed 8 March 2021)

Day, K., H. Campbell, A. Fisher, K. Gibb, B. Hill, A. Rose, and S. N. Jarman. 2019. Development and validation of an environmental DNA test for the endangered Gouldian finch. Endangered Species Research 40:171-182.

Di Minin, E., V. Veach, J. Lehtomäki, F. M. Pouzols, and A. Moilanen. 2014. A quick introduction to Zonation. Conservation Biology Informatics Group, University of Helsinki, Finland.

Dunk, J. R., B. Woodbridge, N. Schumaker, E. M. Glenn, B. White, D. W. LaPlante, R. G. Anthony, R. J. Davis, K. Halupka, P. Henson, B. G. Marcot, M. MerolaZwartjes, B. R. Noon, M. G. Raphael, J. Caicco, D. L. Hansen, M. J. Mazurek, and J. Thrailkill. 2019. Conservation planning for species recovery under the Endangered Species Act: a case study with the Northern Spotted Owl. PLoS ONE 14(1):e0210643.

Dunning, J. B., B. J. Danielson, and H. R. Pulliam. 1992. Ecological processes that affect populations in complex landscapes. Oikos 65:169-175.

Environmental Conservation Online System (ECOS). Available from: https://ecos.fws. gov/ecp/ (Accessed 28 March 2020)

Fleishman, E., J. Anderson, and B. G. Dickson. 2017. Single-species and multiple-species connectivity models for large mammals on the Navajo Nation. Western North American Naturalist 77:237-251.

Fleishman, E., J. Anderson, B. G. Dickson, D. Krolick, J. A. Estep, R. L. Anderson, C. S. Elphick, D. S. Dobkin, and D. A. Bell. 2016. Space use by Swainson's Hawk (Buteo swainsoni) in the Natomas Basin, California. Collabra 2(1):5. 
Forsythe, P., B. Flitz, and S. J. Mullin. 2004. Radio telemetry and post-emergent habitat selection of neonate box turtles (Emydidae: Terrapene carolina) in central Illinois. Herpetological Review 35:333-335.

Gerrard, R., P. Stine, R. Church, and M. Gilpin. 2001. Habitat evaluation using GIS: a case study applied to the San Joaquin kit fox. Landscape and Urban Planning 52:239-255.

Glen, A. S., R. P. Pech, and A. E. Byrom. 2013. Connectivity and invasive species management: towards an integrated landscape approach. Biological Invasions 15:21272138.

Gray, M. E., and B. G. Dickson. 2015. A new model of landscape-scale fire connectivity applied to resource and fire management in the Sonoran Desert, USA. Ecological Applications 25:1099-1113.

Hall, L. S., P. R. Krausman, and M. L. Morrison. 1997. The habitat concept and a plea for standard terminology. Wildlife Society Bulletin 25:173-182.

Hanski, I. 1999. Metapopulation Ecology. Oxford University Press, New York, NY, USA.

Harris, L. D. 1984. The Fragmented Forest: Island Biogeography Theory and the Preservation of Biotic Diversity. University of Chicago Press, Chicago, IL, USA.

Hart, E. E., J. Finnessy, H. B. Rasmussen, M. Butler-Brown, A. B. Muneza, and S. Ciuti. 2020. Precision and performance of a $180 \mathrm{~g}$ solar-powered GPS device for tracking medium to large-bodied terrestrial mammals. Wildlife Biology 2020(3):00669.

Heinrichs, J. A., J. J. Lawler, N. H. Schumaker, L. Walker, D. Cimprich, and A. Bleisch. 2019a. Assessing source-sink stability in the context of management and land-use change. Landscape Ecology 34:259-274.

Heinrichs, J. A., M. S. O’Donnell, C. L. Aldridge, S. L. Garman, and C. G. Homer. 2019 b. Influences of potential oil and gas development and future climate on sage-grouse declines and redistribution. Ecological Applications 29:e01912.

Hitt, N. P., and C. A. Frissell. 2004. A case study of surrogate species in aquatic conservation planning. Aquatic Conservation: Marine and Freshwater Ecosystems 14:625-633.

ICF International (ICF). 2015. Wright Solar Park Habitat Conservation Plan. Available from: ecos.fws.gov/ecp0/conservationPlan/plan?plan_id=4425 (Accessed 8 March 2021)

Jones \& Stokes. 2006. Pacific Gas \& Electric Company San Joaquin Valley Operations and Maintenance Habitat Conservation Plan (includes updated Chapter 4 and Tables 5-3, 5-4 and 5-5, December 2007). J\&S 02-067. Available from: ecos.fws.gov/ ecp0/conservationPlan/plan?plan_id=4229 (Accessed 29 October 2020)

Kadmon, R., O. Farber, and A. Danin. 2004. Effect of roadside bias on the accuracy of predictive maps produced by bioclimatic models. Ecological Applications 14:401413.

Kéry, M., and M. Schaub. 2012. Bayesian population analysis using WinBUGS: a hierarchical perspective. Academic Press, Oxford, UK.

Loss, S.R., L. A. Terwilliger, and A. C. Peterson. 2011. Assisted colonization: integrating conservation strategies in the face of climate change. Biological Conservation 144:92-100.

MacKenzie, D. I., J. D. Nichols, J. E. Hines, M. G. Knutson, and A. B. Franklin. 2003. Estimating site occupancy, colonization, and location extinction when a species is detected imperfectly. Ecology 84:2200-2207. 
MacKenzie, D. I., J. D. Nichols, J. A. Royle, K. P. Pollock, L. L. Bailey, and J. E. Hines. 2006. Occupancy estimation and modeling: inferring patterns and dynamics of species occurrence. Academic Press, San Diego, CA, USA.

Margules, C. R., and R. L. Pressey. 2000. Systematic conservation planning. Nature 405:243-253.

McKelvey, K. S., M. K. Young, W. L. Knotek, K. J. Carim, T. M. Wilcox, T. M. PadgettStewart, and M. K. Schwartz. 2016. Sampling large geographic areas for rare species using environmental DNA: a study of bull trout Salvelinus confluentus occupancy in western Montana. Fish Biology 88:1215-1222.

McRae, B. H. 2006. Isolation by resistance. Evolution 60:1551-1561.

McRae, B. H., B. G. Dickson, T. H. Keitt, and V. B. Shah. 2008. Using circuit theory to model connectivity in ecology, evolution, and conservation. Ecology 89:27122724.

McRae, B. H., S. A. Hall, P. Beier, and D. M. Theobald. 2012. Where to restore ecological connectivity? Detecting barriers and quantifying restoration benefits. PLoS ONE 7(12):e52604.

Mikkonen, N., N. Leikola, A. Lahtinen, J. Lehtomäki, and P. Halme. 2018. Monimuotoisuudelle tärkeät metsäalueet suomessa. Suomen Ympäristökesus, Helsinki, Finland (in Finnish with an English abstract). Available from: helda.helsinki.fi/bitstream/ handle/10138/234359/SYKEra_9_2018.pdf?sequence=1\&isAllowed=y

Moilanen, A. 2007. Landscape Zonation, benefit functions and target-based planning. Unifying reserve selection strategies. Biological Conservation 134:571-579.

Moilanen, A., and H. Kujala. 2008. Zonation spatial conservation planning framework and software: user manual. Version 2.0. Available from: http://cbig.it.helsinki.fi/ software/zonation/

Moilanen, A., H. Kujala, and J. Leathwick. 2009. The Zonation framework and software for conservation prioritization. Pages 196-210 in A. Moilanen, K. A. Wilson, and H. P. Possingham, editors. Spatial Conservation Prioritization: Quantitative Methods and Computational Tools. Oxford University Press, Oxford, UK.

Moilanen, A., F. M. Pouzols, L. Meller, V. Veach, A. Arponen, J. Leppänen, and H. Kujala. 2014. Zonation - spatial conservation planning methods and software Version 4, User Manual. University of Helsinki, Finland.

Morrison, M. L., and L. S. Hall. 2002. Standard terminology: toward a common language to advance ecological understanding and application. Pages 43-52 in J. M. Scott, P. J. Heglund, M. L. Morrison, J. B. Haufler, M. G. Raphael, W. A. Wall, and F. B. Samson, editors. Predicting Species Occurrences: Issues of Accuracy and Scale. Island Press, Washington, D.C., USA.

Nogeire-McRae, T., J. J. Lawler, N. H. Schumaker, B. L. Cypher, and S. E. Phillips. 2019. Land use change and rodenticide exposure trump climate change as the biggest stressors to San Joaquin kit fox. PLoS ONE 14(6):e0214297.

Pulliam, H. R. 1988. Sources, sinks, and population regulation. The American Naturalist 132:652-661.

Rees, H. C., B. C. Maddison, D. J. Middleditch, J. R. M. Patmore, and K. C. Gough. 2014. The detection of aquatic animal species using environmental DNA - a review of eDNA as a survey tool in ecology. Journal of Applied Ecology 51:1450-1459.

Schumaker, N. H., A. Brookes, J. R. Dunk, B. Woodbridge, J. Heinrichs, J. H. Lawler, C. Carroll, and D. LaPlante. 2014. Mapping sources, sinks, and connectivity using 
a simulation model of Northern Spotted Owls. Landscape Ecology 29:579-592.

Schumaker, N. H., and A. Brookes. 2018. HexSim: a modeling environment for ecology and conservation. Landscape Ecology 33:197-211.

Schumaker, N. H., T. Ernst, D. White, J. Baker, and P. Haggerty. 2004. Projecting wildlife responses to alternative future landscapes in Oregon's Willamette Basin. Ecological Applications 14:381-400.

Schumer, G., E. C. Hansen, P. J. Anders, and S. M. Blankenship. 2019. Development of a quantitative polymerase chain reaction assay and environmental DNA sampling methods for giant gartersnake (Thamnophis gigas). PLoS ONE 14(9):e0222493.

Smith, J. A. M., L. R. Reitsma, and P. R. Marra. 2010. Moisture as a determinant of habitat quality for a nonbreeding Neotropical migratory songbird. Ecology 91:2874 2882.

Taylor, P. D., T. L. Crewe, S. A. Mackenzie, D. Lepage, Y. Aubry, Z. Crysler, G. Finney, C. M. Francis, C. G. Guglielmo, D. J. Hamilton, R. L. Holberton, P. H. Loring, G. W. Mitchell, D. R. Norris, J. Pacquet, R. A. Ronconi, J. R. Smetzer, P. A. Smith, L. J. Welch, and B. K. Woodworth. 2017. The Motus Wildlife Tracking System: a collaborative research network to enhance the understanding of wildlife movement. Avian Conservation \& Ecology 12:8.

Urban, D., and T. Keitt. 2001. Landscape connectivity: a graph-theoretic perspective. Ecology 82:1205-1218.

U. S. Fish and Wildlife Service (USFWS). 2011. Revised recovery plan for the Northern Spotted Owl (Strix occidentalis caurina). Pacific Region, Portland, OR, USA.

U. S. Fish and Wildlife Service and National Marine Fisheries Service (USFWS and NFMS). 2016. Habitat conservation planning and incidental take permit processing handbook. Available from: www.fws.gov/endangered/esa-library/index. html\#hcp

Watkinson, A. R., and W. J. Sutherland. 1995. Sources, sinks and pseudo-sinks. Journal of Animal Ecology 64:126-130.

Wilcove, D. S., D. Rothstein, J. Dubow, A. Phillips, and E. Losos. 1998. Quantifying threats to imperiled species in the United States. BioScience 48:607-615.

Wilhere, G. F. 2002. Adaptive management in habitat conservation plans. Conservation Biology 16:20-29.

Winchell, C. S., and P. F. Doherty, Jr. 2008. Using California Gnatcatcher to test underlying models in habitat conservation plans. Journal of Wildlife Management 62:13221327.

Wood, D. A., B. J. Halstead, M. L. Casazza, E. C. Hansen, G. D. Wylie, and A. G. Vandergast. 2015. Defining population structure and genetic signatures of decline in the giant gartersnake (Thamnophis gigas): implications for conserving threatened species within highly altered landscapes. Conservation Genetics 16:1025-1039.

Submitted 7 December 2020

Accepted 19 February 2021

Associate Editor was M. Wieland 